\title{
A Generalized Drucker-Prager Viscoplastic Yield Surface Model for Asphalt Concrete ${ }^{1}$
}

\author{
Yuqing Zhang a,*, Michelle Bernhardt ${ }^{\mathrm{b}}$, Giovanna Biscontin ${ }^{\mathrm{c}}$, Rong Luo ${ }^{\mathrm{a}}$, and Robert L. Lytton ${ }^{\mathrm{a}}$ \\ ${ }^{a}$ Texas A\&M Transportation Institute, College Station, TX, USA \\ Address: CE/TTI Bldg 503, 3135 TAMU, College Station, Texas 77843-3135 \\ ${ }^{b}$ Department of Civil Engineering, University of Arkansas, AR, USA \\ Address: 4190 Bell engineering center, University of Arkansas, Fayetteville, AR 72701 \\ ${ }^{c}$ Department of Engineering, Cambridge University, $U K$ \\ Address: Schofield Centre, High Cross, Madingley Road, Cambridge CB3 OEL, UK \\ *Corresponding author. Tel.: 1-979-739-5366. Fax: 1-979-845-0278 \\ Email addresses: \\ zyqtamu@tamu.edu (Yuqing Zhang) \\ mlbernha@uark.edu (Michelle Bernhardt) \\ gb479@cam.ac.uk (Giovanna Biscontin) \\ rongluo@tamu.edu (Rong Luo) \\ r-lytton@civil.tamu.edu (Robert L. Lytton)
}

\section{Abstract}

A Generalized Drucker-Prager (GD-P) viscoplastic yield surface model was developed and validated for asphalt concrete. The GD-P model was formulated based on fabric tensor modified stresses to consider the material inherent anisotropy. A smooth and convex octahedral yield surface function was developed in the GD-P model to characterize the full range of the internal friction angles from 0 to 90 degrees. In contrast, the existing Extended Drucker-Prager (ED-P) was demonstrated to be applicable only for a material that has an internal friction angle less than 22 degrees. Laboratory tests were performed to evaluate the anisotropic effect and to validate the GD-P model. Results indicated that 1) the yield stresses of an isotropic yield surface model are greater in compression and less in extension than that of an anisotropic model, which can result in an under-prediction of the viscoplastic deformation; and 2) the yield stresses predicted by the GD-P model matched well with the experimental results of the octahedral shear strength tests at different normal and confining stresses. By contrast, the ED-P model over-predicted the octahedral yield stresses, which can lead to an under-prediction of the permanent deformation. In summary, the rutting depth of an asphalt pavement would be underestimated without considering anisotropy and convexity of the yield surface for asphalt concrete. The proposed GD-P model was demonstrated to be capable of overcoming these limitations of the existing yield surface models for the asphalt concrete.

Keywords: Asphalt Concrete; Rutting; Viscoplasticity; Yield Surface; Drucker-Prager; Anisotropy; Convexity.

\footnotetext{
${ }^{1}$ This is an Accepted Manuscript of an article published by Springer in Materials and Structures. The final publication is available online via http://dx.doi.org/10.1617/s11527-014-0425-1
} 


\section{Introduction}

The accuracy of the prediction of an asphalt pavement performance depends primarily on the control of the prediction errors including random errors and systematic errors. The random errors result from the measurements of the material properties or model parameters that are used as the input of the prediction models. The random errors can be minimized by multiple consistent measurements of the same material properties under the same conditions, a process which pavement researchers have frequently employed. The systematic errors are mainly due to the differences between the assumptions of the prediction models and the reality of the material, which has not been well recognized by the researchers. For example, it is very common to assume that asphalt concrete is an isotropic viscoelastic material that has the same properties in compression and in tension. However, the asphalt concrete is an inherently anisotropic material with distinctly different properties in compression and in tension. These assumptions may introduce significant systematic errors in a pavement performance prediction, and sometimes put a pavement design at risk. For example, the isotropic modeling of pavements may lead to an underestimation of tensile and shear stresses associated with permanent deformation and fatigue cracking assessments (Wang et al. 2005). Another example is that the rutting depth of field asphalt pavements were underestimated by using an isotropic constitutive modeling (Oh et al. 2006).

Rutting is one of the major distresses occurring in the asphalt pavements. The accurate prediction of the rutting requires a comprehensive characterization of the viscoplastic properties of the asphalt concrete, which have not been fully addressed due to the complexities of the material. As a viscoelastic-plastic material, asphalt concrete has the following complex material properties associated with rutting:

1) Material properties show significant distinctions in compression, tension and extension. For instance, the yield strength in extension is less than that in compression and the tensile phase angle is greater than the compressive phase angle (Zhang et al. 2012). Since the rutting primarily depends on the material properties in compressive and extensional loads, this paper does not include the characterization of the material properties in tension;

2) Asphalt concrete is a frictional granular material with cohesion. Thus the asphalt concrete will dilate due to viscoplastic damage under a deviatoric shear stress (Bahuguna et al. 2006; Zhu and Sun 2013) and the yield strength will increase at a higher confining pressure (Sousa and Weissman 1994; Sun et al. 2013);

3) Asphalt concrete is an anisotropic viscoelastic material. The vertical to horizontal modulus ratio ranges between 1.2 and 2.0 and the viscoelastic Poisson's ratio can be greater than 0.5. (Zhang et al. 2011; Zhang et al. 2012));

4) Asphalt concrete shows a viscoplastic strain hardening effect before the ultimate yield strength (Subramanian et al. 2013). Thus the yield surface of the asphalt concrete expands as the accumulation of the viscoplastic deformation; 
5) Material behavior of the asphalt concrete is rate and temperature dependent. Thus, material cohesion and strain hardening depend on loading rates and temperatures (Darabi et al. 2012b; Subramanian et al. 2013; Zhang et al. 2013).

As the kernel of the viscoplastic constitutive modeling, a yield surface model is required to account for all of the above properties of the asphalt concrete. In addition, the yield surface model of the asphalt concrete also needs to satisfy the following two mathematical and mechanical criteria:

6) Convexity. Work-hardening materials (e.g., soils, sands, aggregates and asphalt concrete) need to comply with Drucker's Postulate (Drucker 1959), which indicates that the work done during an incremental load is positive and the work done in a loading-unloading cycle is nonnegative. As a consequence, the yield surface of an asphalt concrete must be convex in a stress space. In fact, the convexity of a yield surface has been practically demonstrated by laboratory experiments in all tested materials and had become a fundamental property of plasticity (Bigoni and Piccolroaz 2004; Jiang and Pietruszczak 1988).

7) Smoothness. A non-smooth yield surface (e.g., Mohr-Coulomb criterion which represents an irregular hexagon on the octahedral plane) is not convenient for computational analysis since the corners conflict with convergence of numerical computation (Lin and Bazant 1986). Thus the yield surface of asphalt concrete needs be smooth in the stress space.

The next section discusses the existing yield surface models for asphalt concrete and most recent progresses in the viscoplastic yield modeling. It is found that the existing viscoplastic yield surface models do not fully account for the aforementioned fundamental properties and satisfy the requirements for asphalt concrete. The objective of this study is to develop a generalized yield surface model that can consider all of the above material properties and mathematical requirements so as to comprehensively and accurately characterize the viscoplastic properties of the asphalt concrete. This paper is organized as follows. The next section discusses the advantages and disadvantages of the currently-used yield surface models for asphalt concrete, which is followed by a development of a generalized yield surface model for asphalt concrete. Then the laboratory validation of the proposed yield surface model is presented in detail, which includes testing protocol, testing results and discussions. The last section summarizes the major findings of this study.

\section{Existing Yield Surface Models for Asphalt Concrete}

This section discusses the most widely-used yield surface models for asphalt concrete.

\subsection{Mohr-Coulomb (M-C) Model}

The function of Mohr-Coulomb yield surface model is shown as follows (Fwa et al. 2004):

$$
\tau-\sigma \tan \phi-C=0
$$


where $\tau$ is the yield shear stress; $\sigma$ is the normal stress; $C$ and $\phi$ are cohesion and internal friction angle of asphalt concrete, respectively. Researchers (Tan et al. 1994) found that $\phi$ is primarily a function of aggregate contact and interlocking, which are insensitive to temperature and strain rates. $C$ depends on asphalt mastic which is affected by testing temperatures, strain rates, and properties of binder and fine aggregates. Figure 1 shows an example of MohrCoulomb yield surface which is an irregular hexagon on the octahedral plane (a plane that is equally inclined to the three principal stresses). Thus the M-C model does not satisfy the smoothness requirement.

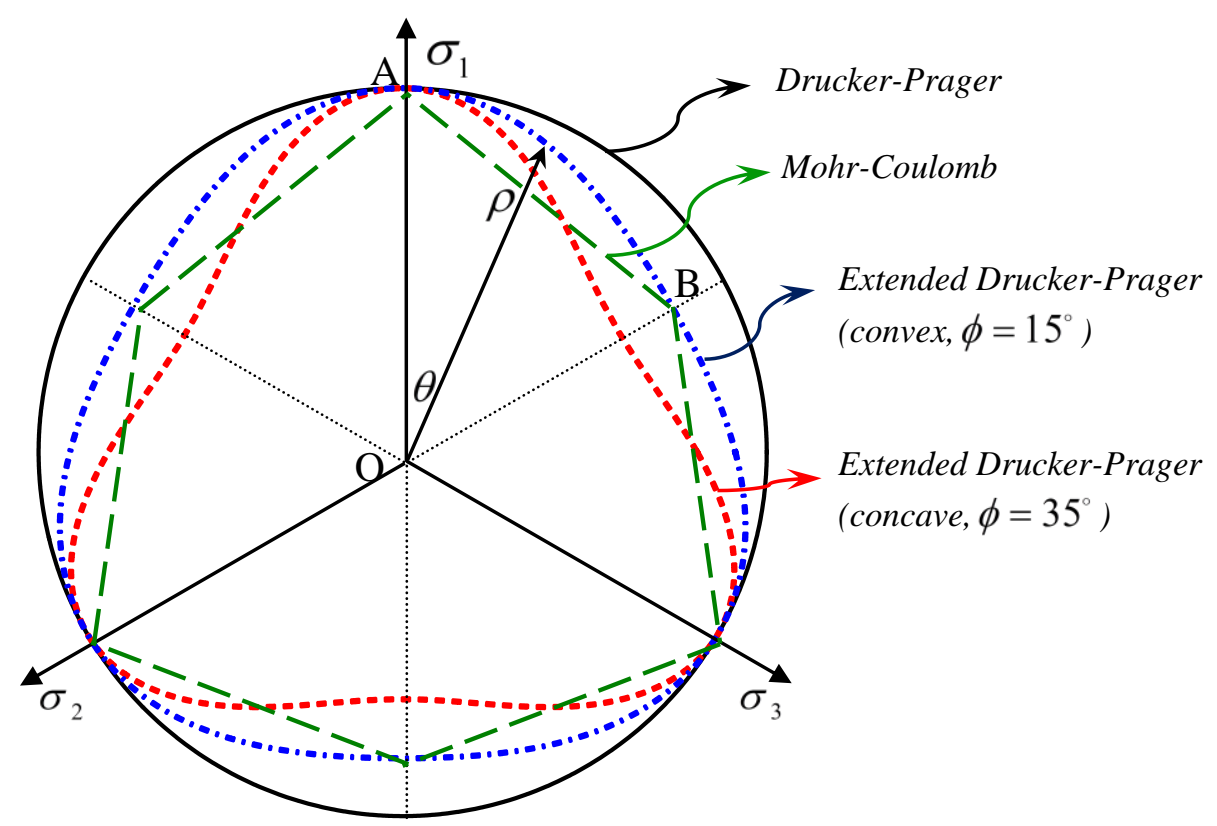

Fig.1 Normalized yield surfaces of Mohr-Coulomb, Drucker-Prager, and Extended Drucker-Prager on an octahedral plane

\subsection{Drucker-Prager (D-P) Model}

Drucker-Prager yield surface model is expressed as (Park et al. 2005; Seibi et al. 2001; Tan et al. 1994):

$$
\sqrt{J_{2}}-\alpha I_{1}-\kappa_{0}=0
$$

where $J_{2}\left(=\frac{1}{2} S_{i j} S_{j i}\right)$ is the second invariant of the deviatoric stress tensor $\left(S_{i j}=\sigma_{i j}-\frac{1}{3} \delta_{i j} I_{1}\right) ; \delta_{i j}$ is Kronecker delta; $I_{1}\left(=\sigma_{k k}\right)$ is the first invariant of stress tensor $\left(\sigma_{i j}\right) . \alpha$ and $\kappa_{0}$ are material properties, which are determined by the cohesion and internal friction angle. By matching the Drucker-Prager yield surface with the external apices of the Mohr-Coulomb criterion (shown in Figure 1), the following relationships are obtained (Chen and Mizuno 1990;

Tashman et al. 2004): 


$$
\begin{gathered}
\alpha=\frac{2 \sin \phi}{\sqrt{3}(3-\sin \phi)} \\
\kappa_{0}=\frac{6 C \cos \phi}{\sqrt{3}(3-\sin \phi)}
\end{gathered}
$$

D-P model is a circle on the octahedral plane as shown in Figure 1, thus the D-P model does not consider the distinction between compression and extension in terms of yield strength.

\subsection{Extended Drucker-Prager (ED-P) Model}

ED-P model is expressed as (Argyris et al. 1974; Darabi et al. 2011; Darabi et al. 2012a; Dessouky and Masad 2006; Saadeh et al. 2007):

$$
\sqrt{J_{2}} \rho(d, \theta)-\alpha I_{1}-\kappa=0
$$

where:

$$
\begin{aligned}
& \rho(d, \theta)=\frac{1}{2}\left[1+\frac{1}{d}+\left(1-\frac{1}{d}\right) \cos (3 \theta)\right] \\
& \theta=\frac{1}{3} \arccos \left[\frac{3 \sqrt{3}}{2} \frac{J_{3}}{\left(J_{2}\right)^{3 / 2}}\right]
\end{aligned}
$$

and, $\rho(d, \theta)$ is a function determining the yield surface shape on the octahedral plane. $\theta$ is the Lode angle that is zero in compression (i.e., OA in Figure 1) and $\pi / 3$ in extension (i.e., OB in Figure 1). $J_{3}\left(=\operatorname{det}\left(S_{i j}\right)\right.$ ) is the third invariant of the deviatoric stress tensor; $\kappa$ is a strain hardening parameter; $d$ is an extension ratio that is the ratio of yield strength in extension to that in compression, which is the length ratio of segment OB to segment OA in Figure 1. $d$ is related to the internal friction angle as follows (Bardet 1990; Maiolino and Luong 2009):

$$
d=\frac{3-\sin \phi}{3+\sin \phi}
$$

$d$ ranges from 1 to 0.5 which corresponds to the internal friction angle from $0^{\circ}$ to $90^{\circ}$. A $d$ value less than 1 indicates that the yield strength in extension is less than that in compression, which is true for asphalt concrete. When $d=1$, the ED-P model is reduced to the D-P model. To ensure the convexity of the ED-P yield surface, $d$ is limited between 1 and 0.778 (Lin and Bazant 1986; Maiolino 2005; Masad et al. 2007), which corresponds to the internal friction angles from 0 to $22^{\circ}$ based on Equation 8. Figure 1 indicates that the ED-P model on the octahedral plane is 
convex when $\phi=15^{\circ}$ whereas concave when $\phi=35^{\circ}$. Figure 2 shows 3-dimentional (3-D) plot of the ED-P models. It is found the 3-D ED-P yield surface is convex when $\phi=9^{\circ}$ whereas concave when $\phi=25^{\circ}$ or $49^{\circ}$. Thus ED-P model only applies to a material with an internal friction angle less than $22^{\circ}$. However, some studies have indicated (Birgisson et al. 2003; Fwa et al. 1997; Zhang et al. 2013) that asphalt concrete commonly has a larger internal friction angle than $22^{\circ}$, mostly greater than $30^{\circ}$. In addition, some studies assigned a constant value of 0.778 to the parameter $d$ , which implicitly hypothesized that the internal friction angle of asphalt concrete is restricted at $22^{\circ}$ (Darabi et al. 2011; Masad et al. 2007). Thus, even though the ED-P model is widely employed in the viscoplastic modeling of the asphalt concrete, a new convex yield surface model is still needed to account for the full range of the internal friction angle from 0 to $90^{\circ}$ for the asphalt concrete.

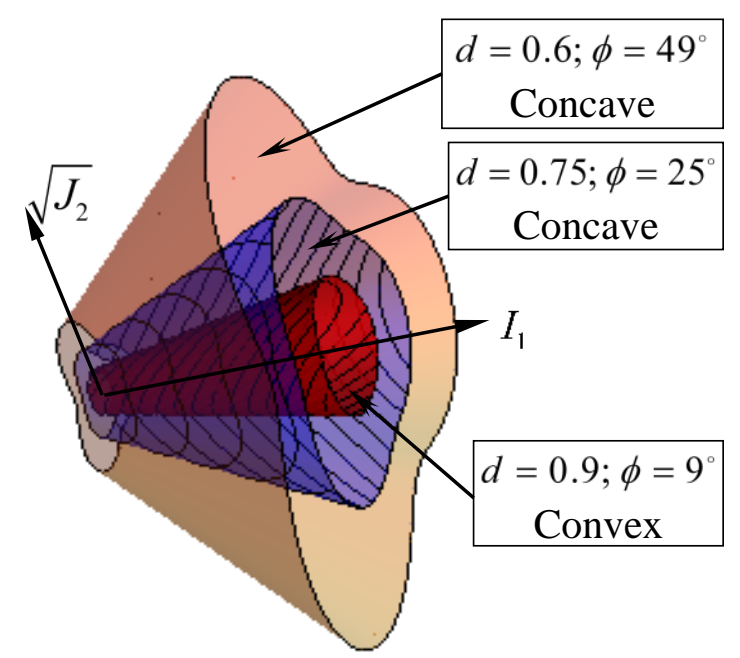

Fig.2 Three dimensional Extended Drucker-Prager (ED-P) yield surfaces with different internal friction angles

\subsection{Extended Matsuoka-Nakai (EM-N) Model}

Bahuguna et al. (2006) extended the Matsuoka-Nakai (M-N) model (Matsuoka and Nakai 1974; Matsuoka and Nakai $1985)$ and proposed the following yield surface equation for asphalt concrete:

$$
I_{1} I_{2}+\alpha I_{3}-H k=0
$$

where $I_{1}\left(=\sigma_{k k}\right), I_{2}\left(=\frac{1}{2}\left(\sigma_{i i} \sigma_{j j}-\sigma_{i j} \sigma_{j i}\right)\right)$ and $I_{3}\left(=\operatorname{det}\left(\sigma_{i j}\right)\right)$ are the first, second and third invariants of the stress tensor, respectively; $H$ is an isotropic hardening parameter; and $k$ is an isotropic hardening variable. MatsuokaNakai (M-N) model is an excellent yield surface model for cohesionless geo-materials (e.g., sands) and it is inherently smooth and convex (Haythornthwaite 1985; Mortara 2008). Yield criteria equivalent to M-N model were presented and evaluated for the Lode dependence of geomaterials (Maiolino and Luong 2009; Mortara 2010). However, EM-N does 
not address the effect of the rate and temperature dependent cohesion and strain hardening of the asphalt concrete. In addition, the EM-N is a function with the third order of stress and the differential of the yield surface is a function with the second order of the stress, which will bring difficulties in numerical calculations.

\subsection{Hierarchical Single-Surface (HISS) Model}

Desai (1986) proposed a hierarchical single-surface model (HISS) to constitutively model geologic materials and the yield surface function has a form as follows:

$$
J_{2}[1-B \cos (3 \theta)]^{m}-\left[\gamma\left(I_{1}+S\right)^{2}-\alpha\left(I_{1}+S\right)^{n}\right]=0
$$

where $\gamma$ is a softening parameter; $\alpha$ is a hardening parameter, $S$ is a cohesion related parameter; $n$ is a parameter

determining the shape of the yield surface in deviatoric-hydrostatic stress $\left(\sqrt{J_{2}} \sim I_{1}\right)$ space (meridian plane); $B$ and $m$ are parameters determining the shape of the yield surface on the octahedral plane. The HISS model was later extended to consider more complex properties of soils such as anisotropic hardening (Somasundaram and Desai 1988) and cyclic behavior (Wathugala and Desai 1993). Pavement researchers used Desai's HISS model to model asphalt concrete by setting $m$ as -0.5 (Huang et al. 2004; Muraya et al. 2009) and model sand/aggregate base by setting $m$ as 1 (Bonaquist and Witczak 1996). The temperature dependent viscoplasticity of asphalt mixtures was addressed by using the model coefficients as functions of temperatures (Huang et al. 2004).

Several problems exist in the HISS model when applied to model asphalt concrete: 1) to ensure a convex yield surface for a full range of the internal friction angle from $0^{\circ}$ to $90^{\circ}$, the value of $m$ must be 0.229 (Van Eekelen 1980 ); 2) the HISS model exhibits a spindle shape and shows a nonlinear curve of its yield surface. However, at a confinement stress level of the field asphalt pavement, the yield surface of asphalt concrete remains linear in the meridian plane according to the measurements in the literature (Masad et al. 2007; Seibi et al. 2001); 3) HISS model is a function with the second order of the stress; and 4) complicated laboratory experiments are required for the determinations of the six fitting parameters in the HISS model.

\subsection{Comparison of Asphalt Concrete Yield Surface Models}

Table 1 evaluates the existing yield surface models to determine if they can characterize the properties of the asphalt concrete that are discussed in the Introduction section. One can find that none of the existing models can provide a complete characterization. In a preliminary study (Zhang et al. 2013), the authors employed the ED-P model for the asphalt concrete yield surface but modified it by temperature and strain rate dependent cohesion and strain hardening. The work in this preliminary study was not a complete development of the yield surface model as the anisotropy of the material, smoothness and convexity of the yield surface were not taken into account. In the next section, the authors will propose a comprehensive yield surface model entitled the Generalized Drucker-Prager (GD-P) model to consider all of the material properties of the asphalt concrete as shown in Table 1. 
Table 1 Evaluations of existing yield surface models for asphalt concrete

\begin{tabular}{|c|c|c|c|c|c|c|c|}
\hline $\begin{array}{c}\text { Yield } \\
\text { Surface } \\
\text { Models }\end{array}$ & $\begin{array}{c}\mathbf{1}) \\
\text { Compression } \\
\text { versus } \\
\text { Extension } \\
\end{array}$ & $\begin{array}{c}(2) \\
\text { Friction } \\
\text { and } \\
\text { Cohesion } \\
\end{array}$ & $\begin{array}{c}\text { (3) } \\
\text { Material } \\
\text { inherent } \\
\text { anisotropy }\end{array}$ & $\begin{array}{c}(4) \\
\text { Strain } \\
\text { Hardening }\end{array}$ & $\begin{array}{c}(5) \\
\text { Temperature } \\
\text { and Rate } \\
\text { Dependence } \\
\end{array}$ & $\begin{array}{c}(6) \\
\text { Convexity }\end{array}$ & $\begin{array}{c}\text { (7) } \\
\text { Smooth- } \\
\text {-ness }\end{array}$ \\
\hline $\mathrm{M}-\mathrm{C}$ & $\sqrt{ }$ & $\sqrt{ }$ & $x$ & $\&$ & $\$$ & $\sqrt{ }$ & $x$ \\
\hline D-P & $x$ & $\sqrt{ }$ & $\$$ & $\&$ & $\$$ & $\sqrt{ }$ & $\sqrt{ }$ \\
\hline ED-P & $\sqrt{ }$ & $\sqrt{ }$ & $\$$ & $\sqrt{ }$ & $\$$ & $x$ & $\sqrt{ }$ \\
\hline EM-N & $\sqrt{ }$ & $\sqrt{ }$ & $\$$ & $\&$ & $\$$ & $\sqrt{ }$ & $\sqrt{ }$ \\
\hline HISS & $\sqrt{ }$ & $\sqrt{ }$ & $\$$ & $\sqrt{ }$ & $\sqrt{ }$ & $x$ & $\sqrt{ }$ \\
\hline GD-P & $\sqrt{ }$ & $\sqrt{ }$ & $\sqrt{ }$ & $\sqrt{ }$ & $\sqrt{ }$ & $\sqrt{ }$ & $\sqrt{ }$ \\
\hline Note: & \multicolumn{7}{|c|}{$\begin{array}{l}\sqrt{ }(\times) \text { : yield surface model can(not) characterize the corresponding property of asphalt concrete; } \\
\$: \text { the existing model does not consider the corresponding property but can be addressed by using } \\
\text { the same method as in this paper, e.g., use modified stress in yield function to consider anisotropy; } \\
\text { use temperature and rate dependent strain hardening function in yield surface models. } \\
\&: \text { an independent strain hardening function can be incorporated into the existing model }\end{array}$} \\
\hline
\end{tabular}

\section{Development of A Comprehensive Yield Surface Model for Asphalt Concrete}

In this section, a convex yield surface is derived in terms of modified stresses for the viscoplastic yield surface characterization of the asphalt concrete.

\subsection{Modified Stress for Characterization of Inherent Anisotropy}

Studies (Pickering 1970; Tobita and Yanagisawa 1992) on geo-materials indicated that, without consideration of inherent anisotropy caused by the preferentially oriented granular particles (e.g., soils, sands, and aggregates) in the constitutive formulation, some important material properties such as non-coaxiality and dilation would not be properly accounted for. The constitutive models based on modified stresses had successfully captured the material anisotropic property where the modified stresses were obtained by modifying the nominal stress with a fabric tensor (Oda and Nakayama 1989; Tobita 1989). It was also suggested that the isotropic yield condition in terms of the modified stresses could lead to an anisotropic yielding and hardening nature of the granular materials with less mathematical complexities as only the isotropic material constants were needed (Tobita and Yanagisawa 1988). This method has been extensively adopted by researchers to study the anisotropic yield or failure criteria for geomaterials (Gao et al. 2010; Kong et al. 2013; Shaverdi et al. 2013).

As a granular material, asphalt concrete exhibits the inherent anisotropy due to the inclined aggregates that tend to be oriented along the horizontal direction. Pavement researchers (Masad et al. 1998; Tashman et al. 2002) adopted the same fabric tensor concept to account for the anisotropy during the viscoplastic constitutive modeling of asphalt concrete. The authors (Zhang et al. 2011) improved the fabric tensor using a modified vector magnitude $\left(\Delta^{\prime}\right)$ which considered not only the aggregate orientation, but the size and shape of both the coarse and fine aggregates. A 
high correlation was obtained between $\Delta^{\prime}$ and the anisotropic modulus ratio of asphalt concrete. The modified fabric tensor is written as:

$$
\left[F_{i j}^{\prime}\right]=\frac{1}{3+\Delta^{\prime}}\left[\begin{array}{ccc}
1-\Delta^{\prime} & 0 & 0 \\
0 & 1+\Delta^{\prime} & 0 \\
0 & 0 & 1+\Delta^{\prime}
\end{array}\right]
$$

where $\Delta^{\prime}$ is the modified vector magnitude that is determined as:

$$
\Delta^{\prime}=\frac{1}{A_{0}} \sqrt{\left(\sum_{k=1}^{M} \rho^{(k)} \lambda^{(k)} \sin 2 \theta_{k}\right)^{2}+\left(\sum_{k=1}^{M} \rho^{(k)} \lambda^{(k)} \cos 2 \theta_{k}\right)^{2}}
$$

where $A_{0}=\sum_{k=1}^{M}\left(\rho^{(k)} \lambda^{(k)}\right) ; \rho^{(k)}, \lambda^{(k)}$ and $\theta_{k}$ are area, aspect ratio and inclination angle of an aggregate,

respectively, which can be accurately and quickly measured by a lateral surface scanning test (Zhang et al. 2011). $\Delta^{\prime}$ theoretically ranges between 0 and 1 , where $\Delta^{\prime}=0$ indicates an isotropic condition and $\Delta^{\prime}=1$ implies a fully crossanisotropic condition.

A modified stress tensor is introduced to combine the stress tensor and the fabric tensor as follows (Oda 1993; Tobita and Yanagisawa 1988; Yang et al. 2008):

$$
\bar{\sigma}_{i j}=\frac{1}{6}\left(\sigma_{i n} F_{n j}^{\prime-1}+F_{i n}^{\prime-1} \sigma_{n j}\right)
$$

where, $\bar{\sigma}_{i j}$ is the fabric tensor modified stress tensor that considers inherent anisotropy; $\sigma_{i j}$ is the nominal stress tensor calculated using isotropic constitutive models. $F_{n j}^{\prime-1}$ is the inverse of the modified fabric tensor. If a fourth-order fabric tensor is defined as:

$$
F_{i m n j}=\frac{1}{6}\left(\delta_{i m} F_{n j}^{\prime-1}+F_{i m}^{\prime-1} \delta_{n j}\right)
$$

where, $\delta_{i j}$ is Kronecker delta tensor; the modified stress becomes:

$$
\bar{\sigma}_{i j}=F_{i m n j} \sigma_{m n}
$$

In this paper, the stresses are modified by the fabric tensor and indicated by a head bar. The following proposed yield surface model also employs the modified stress to account for the inherent anisotropy of the asphalt concrete. 


\subsection{Development of a Yield Surface Model for Asphalt Concrete}

A Generalized Drucker-Prager (GD-P) yield surface function for asphalt concrete is proposed as:

$$
\sqrt{\bar{J}_{2}} \rho(\theta, d)-\alpha \bar{I}_{1}-\kappa a_{T} a_{\dot{\varepsilon}}=0
$$

where $\bar{J}_{2}\left(=\frac{1}{2} \bar{S}_{i j} \bar{S}_{j i}\right)$ is the second invariant of the modified deviatoric stress tensor $\left(\bar{S}_{i j}=\bar{\sigma}_{i j}-\frac{1}{3} \delta_{i j} \bar{I}_{1}\right) ; \bar{I}_{1}\left(=\bar{\sigma}_{k k}\right)$ is the first invariant of the modified stress tensor $\left(\bar{\sigma}_{i j}\right)$ that is defined in Equation 15. $\alpha$ is the slope of the yield surface on the meridian plane that can be related to internal friction angle using Equation 3.

The term $\kappa a_{T} a_{\dot{\varepsilon}}$ was proposed by the authors in a previous paper and had been demonstrated by laboratory tests to be capable of accounting for the effects of temperature and strain rate on the cohesion and strain hardening of the asphalt concrete (Zhang et al. 2013). $a_{T}$ is a temperature factor; $a_{\dot{\varepsilon}}$ is a strain rate factor; $\kappa$ is a strain hardening function and they are expressed as:

$$
\begin{aligned}
& \kappa=\kappa_{0}+\kappa_{1}\left[1-\exp \left(-\kappa_{2} \varepsilon_{e}^{v p}\right)\right] \\
& a_{T}=\exp \left[\frac{\Delta E_{T}}{R}\left(\frac{1}{T}-\frac{1}{T_{0}}\right)\right] \\
& a_{\dot{\varepsilon}}=\left(\frac{\dot{\varepsilon}}{\dot{\varepsilon}_{0}}\right)^{\kappa_{3}}
\end{aligned}
$$

where $\kappa_{0}, \kappa_{1}$ and $\kappa_{2}$ are material parameters determined at the reference temperature $\left(T_{0}\right)$ and at the reference strain rate $\left(\dot{\varepsilon}_{0}\right) ; \kappa_{0}$ is defined by material cohesion and friction angle as shown in Equation $4 ; \kappa_{1}$ determines the amplitude of the strain hardening; $\kappa_{2}$ defines the strain hardening rate; $\varepsilon_{e}^{v p}$ is the effective viscoplastic strain, which has different expressions when different yield surfaces and flow rules are used. For instance, when the von Mises yield surface and associated flow rule are used, the incremental effective plastic strain is given as: $d \varepsilon_{e}^{p}=\sqrt{2 / 3 d \varepsilon_{i j}^{p} d \varepsilon_{i j}^{p}}$ where $d \varepsilon_{i j}^{p}$ is the incremental plastic strain tensor. The generalized expression of $\varepsilon_{e}^{v p}$ will be presented in a future study. $a_{T}$ is modeled by an Arrhenius temperature function where $\Delta E_{T}$ is the activation energy, $\mathrm{J} / \mathrm{mol}$ and $R$ is the universal gas constant, $8.314 \mathrm{~J} / \mathrm{mol} \cdot \mathrm{K} ; a_{\dot{\varepsilon}}$ is modeled by a power function where $\dot{\varepsilon}$ is the rate of total strain of interest, $1 / \mathrm{sec}$. The activation energy $\Delta E_{T}$ and $\kappa_{3}$ are used as model parameters that can be determined by performing uniaxial strength tests at different temperatures and strain rates, respectively. 
The function $\rho(\theta, d)$ in the GD-P model differs from the expression in Equation 6 of the ED-P model, and is derived in Appendix A to provide a convex yield surface for the full range of the internal friction angle from $0^{\circ}$ to $90^{\circ}$ that is:

$$
\rho(\theta, d)=\mu \cos \left[\frac{1}{3} \arccos (\gamma \cos 3 \theta)\right]
$$

where:

$$
\left\{\begin{array}{l}
\mu=\frac{2 \sqrt{1-d+d^{2}}}{\sqrt{3} d} \\
\gamma=-\frac{3 \sqrt{3}}{2} \frac{(1-d) d}{\left(1-d+d^{2}\right)^{3 / 2}}
\end{array}\right.
$$

and $d$ is the extension ratio: $d=(3-\sin \phi) /(3+\sin \phi)$ as shown in Equation 8 and $\phi$ is the internal friction angle. $\theta$ is the Lode angle that is defined by Equation 7 but using modified invariants (i.e., $\bar{J}_{2}$ and $\bar{J}_{3}=\operatorname{det}\left(\bar{S}_{i j}\right)$ ). $\rho(\theta, d)$ is a function that defines the yield surface shape on the octahedral plane and determines the convexity of the yield surface. Appendix A proves that:

$$
\begin{cases}\rho(\theta=0, d)=1 & \text { in compression } \\ \rho\left(\theta=\frac{\pi}{3}, d\right)=\frac{1}{d} & \text { in extension }\end{cases}
$$

GD-P model is a very general yield surface model. When the difference between extension and compression is neglected (i.e., $d=1$ and $\rho(\theta, d)=1$ ), the GD-P model is reduced to Drucker-Prager model; when the cohesion is neglected ( $\kappa=0$ ), the GD-P model becomes the Matsuoka-Nakai model. In addition, the GD-P model also satisfies the three requirements of Lode dependence for pressure-sensitive materials (Bardet 1990): 1) extension ratio ( $\rho(0) / \rho\left(\frac{\pi}{3}\right)=d$ according to Equation 22); 2) smoothness $\left(\rho^{\prime}(0)=\rho^{\prime}\left(\frac{\pi}{3}\right)=0\right)$; and 3) convexity that is inherited form the Matsuoka-Nakai model.

Figure 3 plots three dimensional (3-D) GD-P yield surfaces and Figure 4 shows the yield surface of the GD-P model on the octahedral plane with different internal friction angles. One can find that the GD-P model always provides a smooth and convex yield surface when the internal friction angle varies from $0^{\circ}$ to $90^{\circ}$. The yield strength in extension is less than that in compression, which is quantified by the extension ratio, i.e., $d$. It can be proved that the GD-P yield surface coincides with the apices of the Mohr-Coulomb yield surface on the octahedral plane. Thus the GD- 
P model can be regarded as a smoothed Mohr-Coulomb yield surface which considers the anisotropy, strain hardening, temperature and strain rate effects.

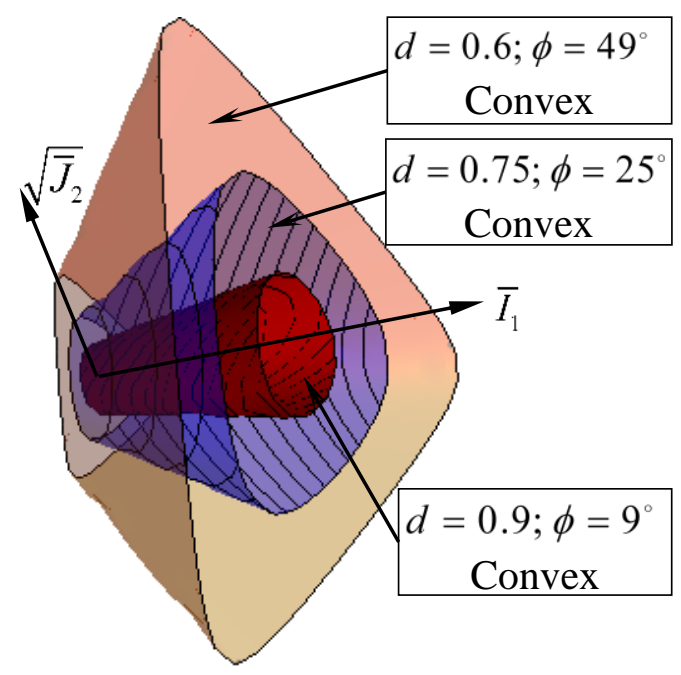

Fig.3 Three dimensional Generalized Drucker-Prager (GD-P) yield surfaces wiht different internal friction angles

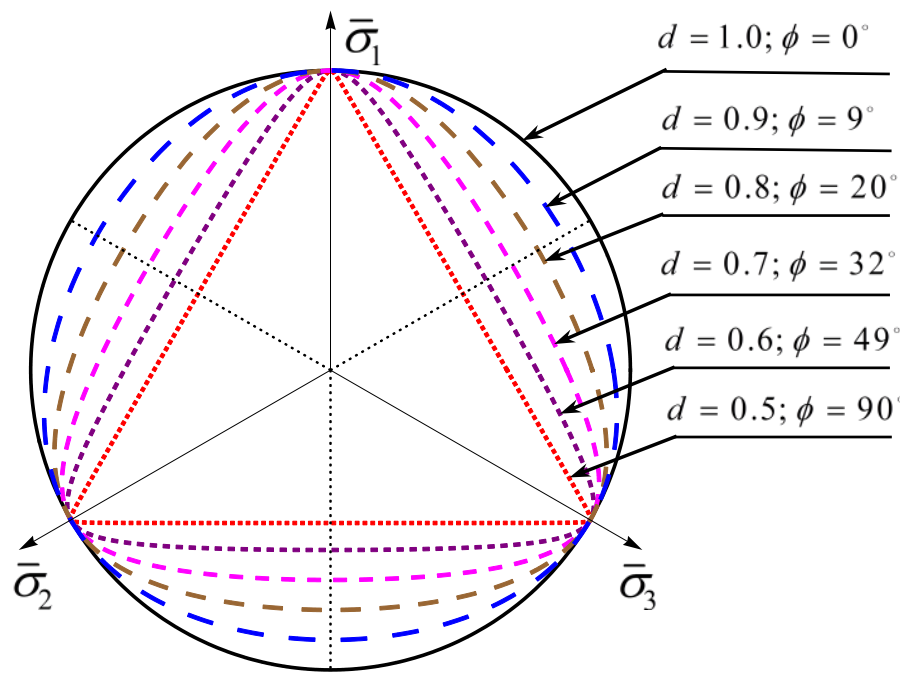

Fig.4 Generalized Drucker-Prager (GD-P) yield surfaces on octahedral plane with different internal friction angles

\section{Effect of Anisotropy on Yield Surface of Asphalt Concrete}

Literature studies (Oh et al. 2006; Wang et al. 2005) illustrated an underestimation of rutting of asphalt pavements if using isotropic modulus in constitutive modeling of asphalt concrete. This section explains the fundamental reason for this observation from the point of the effect of anisotropy on the yield surface of the asphalt concrete. 


\subsection{Laboratory Characterization of Asphalt Concrete's Anisotropy}

The inherent anisotropy of the asphalt concrete is caused by the preferentially oriented aggregates resulting from the compaction during pavement construction. It is quantified by the modified vector magnitude $\left(\Delta^{\prime}\right)$ that is defined in Equation 12. Theoretically, $\Delta^{\prime}$ ranges from 0 to 1 which indicates from isotropy to anisotropy. The authors proposed a fast and simple test that is the lateral surface scanning (hot-dog) test to determine $\Delta^{\prime}$ (Zhang et al. 2011). In this test, a cylindrical specimen (100 $\mathrm{mm}$ in diameter and $150 \mathrm{~mm}$ in height) was laid horizontally on an automatic rotator (made of a hot-dog cooker device) which rotated the sample at a constant speed. The lateral surface of the sample was scanned by a portable digital scanner to obtain a lateral surface image, which was then analyzed to determine the aggregates' properties including the inclination angle, the area, and the aspect ratio of the aggregates on the image. These measurements were used to calculate the modified vector magnitude in Equation 12. More details about the test and the analysis can be found in the reference (Zhang et al. 2011).

The lateral surface scanning tests were adopted in this study and performed on asphalt concrete specimens which employed a Type C (coarse surface) dense aggregate gradation specified by the Texas Department of Transportation (TxDOT) (2004). Two binders (i.e., NuStar PG67-22 and Valero PG64-16), two air void contents (i.e., $4 \%$ and $7 \%$ ) and three aging periods $(0,3,6$-month aging) were used for the asphalt concrete specimen preparation. Figure 5 shows that the measured $\Delta^{\prime}$ for the tested specimens and the values of $\Delta^{\prime}$ vary from 0.2 to 0.5 , which is consistent with the literature measurements (Zhang et al. 2011). Figure 5 indicates that the inherent anisotropy of the asphalt concrete is independent of binder types, air void contents, and aging periods, which is also the reason for the data variation (shown as the sample-to-sample variability). In fact, $\Delta^{\prime}$ depends on the aggregate properties including aggregate shape, size and orientation, which are related to the aggregate gradation and the compaction effort during the specimen fabrication.

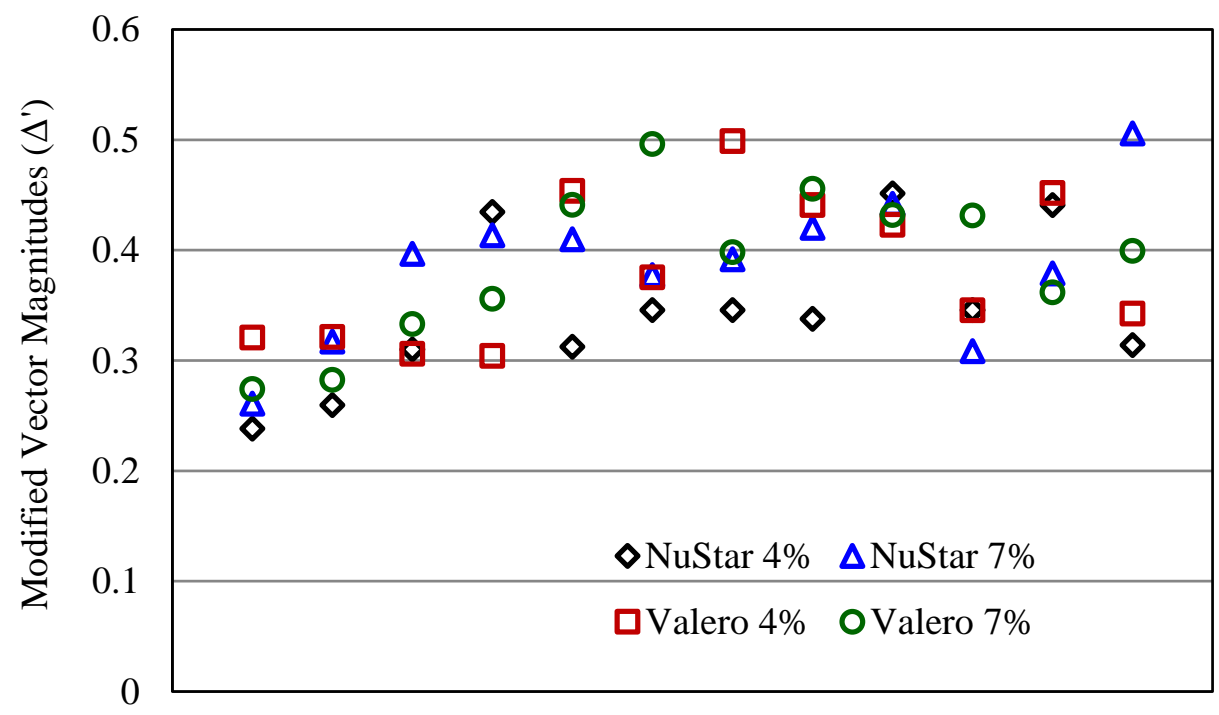

Fig.5 Measured modified vector magnitudes of asphalt concrete 


\subsection{Effect of Anisotropy on the Yield Surface of Asphalt Concrete}

To quantify the effect of anisotropy on the yield surface of the asphalt concrete, three yield surfaces were plotted in Figure 6 based on the GD-P model, where $\sigma_{1}, \sigma_{2}$ and $\sigma_{3}$ are nominal principal stresses. The three yield surfaces illustrate different anisotropic levels including isotropy $\left(\Delta^{\prime}=0\right)$, low anisotropy $\left(\Delta^{\prime}=0.25\right)$ and high anisotropy ( $\Delta^{\prime}=0.5$ ). Figure 6 indicates that, when the asphalt concrete is modeled as an isotropic material, the yield strength is greater in triaxial compression while less in triaxial extension condition than the yield strength of an anisotropic asphalt concrete. As a result, the predicted viscoplastic deformation will be underestimated in compression and overestimated in extension compared to the field asphalt concrete which is an inherently anisotropic material.

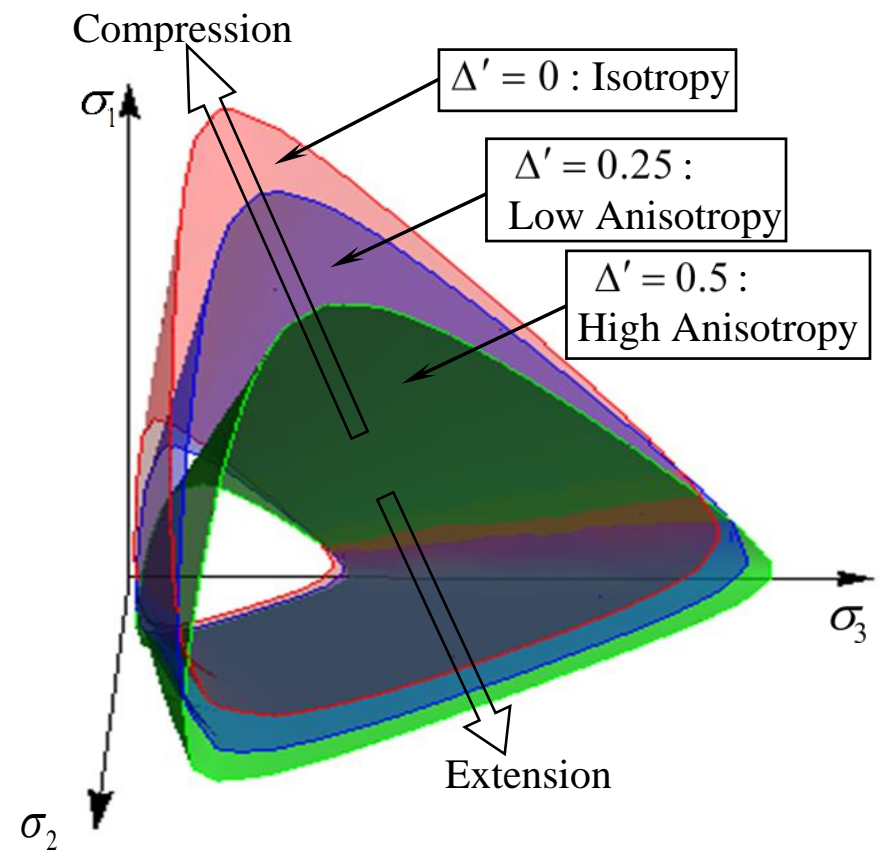

Fig. 6 Generalized Drucker-Prager (GD-P) yield surfaces of asphalt concrete with different levels of anisotropy quantified by modified vector magnitude (i.e., $\Delta^{\prime}$ )

The effect of anisotropy on rutting development can be further deduced as follows: the asphalt concrete immediately beneath a tire load is subjected to triaxial stresses in compression which lead to the development of the vertical viscoplastic deformation (i.e., increase of rutting depth). The asphalt concrete away from the tire load is subjected to triaxial stresses in extension which result in the reversal of the vertical viscoplastic deformation (i.e., recovery of rutting depth). Thus, based on Figure 6, when using an isotropic yield surface, the development of the vertical viscoplastic deformation due to the compressive stresses is under-predicted while the reversal of the vertical viscoplastic deformation caused by the extensional stresses is over-predicted, both of which result in an underestimation of the rutting in the asphalt pavement. Therefore, the isotropic yield surface model may under-predict the rutting depth and reduce the reliability of pavement design. The anisotropy of asphalt concrete should be addressed in material constitutive models and/or in the calibration of pavement performance predictions. This paper provides a straight 
forward method using the modified stresses in the yield surface function to account for the inherent anisotropy of the asphalt concrete.

\section{Laboratory Validation of Yield Surface Models for Asphalt Concrete}

The laboratory validation for the term $\kappa a_{T} a_{\dot{\varepsilon}}$ of the GD-P model has been performed in the previous study (Zhang et al. 2013), which demonstrated the effects of temperature and strain rate on cohesion and strain hardening. In this study, laboratory tests were performed to compare the ED-P model with the proposed GD-P yield surface model and validate the latter.

\subsection{Testing Materials and Protocols}

Octahedral shear strength tests (OSST) at different normal and confining stresses were conducted to validate the proposed GD-P yield surface model on the octahedral plane for the asphalt concrete. The materials used in the mixture were Valero binder and a commonly-used Texas Hanson limestone. The aggregate gradation was Type C as specified by TxDOT (2004). The optimum asphalt content was determined based on TxDOT specification (TxDOT 2008) as 4.4\%. The asphalt mixtures were compacted using a Superpave gyratory compactor at two target air void contents namely $4 \%$ and $7 \%$, respectively.

Figure 7 shows the octahedral shear test configuration. The tests were performed using a multi-directional direct simple shear testing device developed at Texas A\&M University and more information about the device can be found in the literature (Rutherford 2012; Rutherford and Biscontin 2013). The cylindrical specimen has a diameter of $100 \mathrm{~mm}$ and a height of $35 \mathrm{~mm}$, which complies with a minimum length-to-height ratio of 3 (Weissman et al. 1999). However, a smaller size of the specimen was adopted in this test compared to the standard Superpave Shear Test (SST that uses $150 \mathrm{~mm}$ in diameter and $50 \mathrm{~mm}$ in height). The reason is that the OSSTs performed in this study are shear strength tests with confinement, which requires a relatively high shear load to fail the asphalt concrete sample. As a contrast, the SSTs such as the Frequency Sweep at Constant Height Test and Simple Shear at Constant Height Test commonly use repeated loads and have an upper limit for the maximum shear stress level. Thus the test protocol of OSST and the capacity of the test machine restrict the maximum dimension of the asphalt concrete specimen that can be used in the study. More OSST validation tests on larger sample size will be performed by the shear test machine with a higher loading capacity.

The specimens were glued between two end-caps. The top end-cap was attached using an assembly clamp to the machine axial loading platen which can apply the normal load (i.e., $\sigma$ that is a normal stress in the axial direction of the specimen). The bottom end-cap was attached to a horizontally moveable shear loading platen which can provide the shear load (i.e., $\tau$ that is a shear stress in the horizontal direction). The whole system was enclosed in an airtight pressure chamber which can provide a constant air confining pressure (i.e., $p$ that is a confining pressure applied in all 
directions). Latex membrane was not used for the sample of the OSSTs. The reason is that the OSSTs are failure tests which keep increasing the shear deformation until the specimen fails. The total shear deformation is significantly greater than that of the conventional SSTs in the literature studies. Using a latex membrane may introduce a constraint effect on the deformed specimens and influence the yielding and failure of the asphalt concrete specimens during the strength tests. In addition, the samples tested in this study are dense asphalt concrete and they are cored and cut from bigger asphalt concrete cylinder. The lateral surface of the samples become smooth and impermeable during coring and cutting operations, which restricts the connection of the internal air voids with the outside confining air. Thus the internal air pressure of the sample cannot build up with the confining pressure. The confining pressure is therefore effectively applied on the structure of the asphalt concrete and the test results in the next section also show that different yield shear stresses are obtained at different confining pressures.

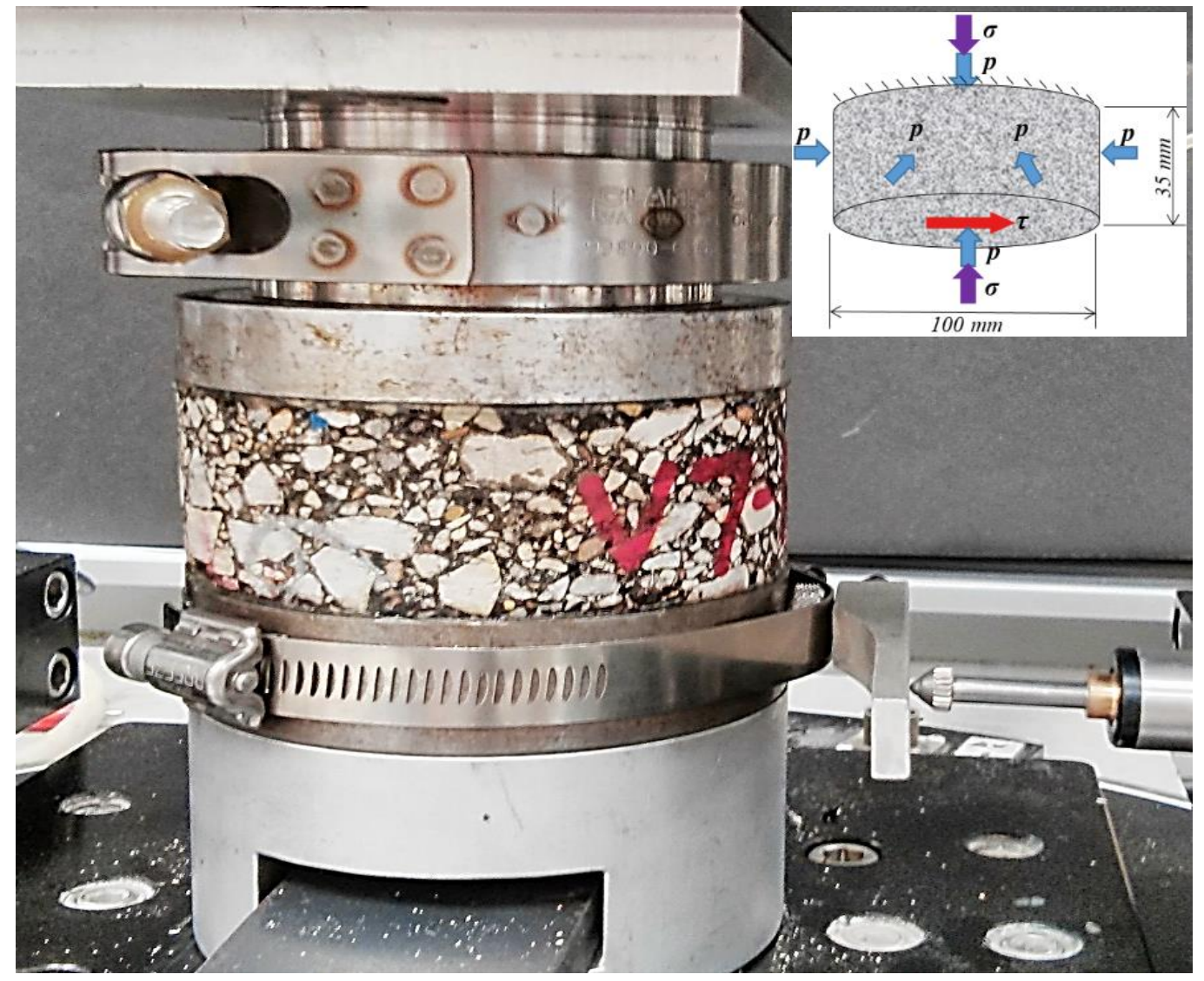

Fig.7 Configuration of octahedral shear strength tests and loading conditions

To evaluate the shear yield stress on the octahedral plane, the first stress invariant (i.e., $\left.I_{1}=\sigma_{k k}=\sigma_{11}+\sigma_{22}+\sigma_{33}\right)$ needs to remain constant during the shearing process. The purpose of this is to ensure that the asphalt concrete yields in the same octahedral plane and the octahedral yield stresses within this single plane can be evaluated at different Lode angles and used to validate the convexity and accuracy of the proposed yield surface model. The stress state of the specimen in OSST is approximately expressed as: 


$$
\sigma_{i j}=\left[\begin{array}{ccc}
\sigma+p & \tau & 0 \\
\tau & p & 0 \\
0 & 0 & p
\end{array}\right]
$$

$I_{1}=\sigma+3 p$ was controlled constantly at $400 \mathrm{kPa}$ by applying seven different $p$ and $\sigma$ levels, which are shown as levels A, B, C, D, E, F, and G in Table 2. At each test level, $p$ and $\sigma$ remained unchanged and the shear deformation was increased at a constant shear strain rate that is 286 micro-strains/sec corresponding to a shear displacement rate of $0.01 \mathrm{~mm} / \mathrm{sec}$. The shear stress was found to increase with the shear deformation until a peak stress and then decreased as the shear deformation increased as shown in Figure 8. A linear variable differential transformer (LVDT) was used to record the horizontal shear displacement, which was also compared with the machine deformation. Since the normal load (i.e., $\sigma$ ) was controlled at constant in the shear process, the asphalt concrete tends to dilate and the height of the sample increases, which was recorded by the displacement gauge of the testing machine. The shear load was applied on the specimen at a constant temperature of $50^{\circ} \mathrm{C}$ until the material ruptured or significant cracks were observed. Only one loading rate and one temperature were employed in the shear tests since the shape of the octahedral yield surface only depends on aggregate skeleton (i.e., internal friction angle) that is independent of loading rate and temperature. This conclusion will be verified by the results of the octahedral shear tests. The shear stress (i.e., $\tau$ in Equation 23) was determined as the initial yield stress using the stress-pseudostrain method proposed by the authors (Zhang et al. 2013). At least two replicates were tested for each stress level and a third replicate was tested if a high variation was observed. Table 2 includes the average measured shear yield stress for each stress level.

Table 2 Test parameters of octahedral shear strength tests and yield shear stress results

\begin{tabular}{|c|c|c|c|c|}
\hline \multirow[b]{2}{*}{ Stress Case No. } & \multirow{2}{*}{$\begin{array}{c}\text { Confining Pressure } \\
p \\
\mathbf{k P a} \\
\end{array}$} & \multirow{2}{*}{$\begin{array}{c}\text { Normal Load } \\
\sigma \\
\text { kPa }\end{array}$} & \multicolumn{2}{|c|}{ Average Measured Yield Shear Stress } \\
\hline & & & $\begin{array}{c}\tau @ 4 \% \\
\mathbf{k P a}\end{array}$ & $\begin{array}{c}\tau @ \mathbf{7 \%} \\
\mathbf{k P a} \\
\end{array}$ \\
\hline A & 0 & 400 & 230 & 190 \\
\hline B & 33 & 300 & 250 & 205 \\
\hline $\mathrm{C}$ & 67 & 200 & 255 & 225 \\
\hline $\mathrm{D}$ & 100 & 100 & 255 & 220 \\
\hline $\mathrm{E}$ & 133 & 0 & 237 & 220 \\
\hline $\mathrm{F}$ & 167 & -100 & 220 & 195 \\
\hline $\mathrm{G}$ & 200 & -200 & 195 & 160 \\
\hline Materials & \multicolumn{4}{|c|}{$\begin{array}{l}\text { Air voids: } 4 \% \text { and } 7 \% \text { by volume } \\
\text { Binder: Valero PG64-16 } \\
\text { Aggregate: Texas limestone }\end{array}$} \\
\hline Test Parameters & \multicolumn{4}{|c|}{$\begin{array}{l}\text { First stress invariant, } I_{l}=400 \mathrm{kPa} \\
\text { Shear rate: } 286 \mathrm{micron} / \mathrm{sec}(0.01 \mathrm{~mm} / \mathrm{sec}) \\
\text { Test temperature: } 50^{\circ} \mathrm{C} \\
\text { Replicates: } 2 \text { or } 3\end{array}$} \\
\hline
\end{tabular}




\subsection{Testing Results and Discussions}

The octahedral shear strength tests show volumetric dilation of the asphalt concrete specimens. Figure 8 shows curves of shear stress versus shear strain for two replicates and the corresponding vertical dilation of the specimen which keeps increasing as the shear strain accumulates. The rate of dilation increases before the peak load and then decreases when the shear load declines. The inflection point of the dilation occurs at the moment corresponding to the peak shear load. In fact, as a granular material, the asphalt concrete dilates when subjected to a shear load. In this test, the normal load $(\sigma)$ and the confining pressure $(p)$ were strictly maintained at constant levels so that the first stress invariant $\left(I_{l}\right)$ remained unchanged at $400 \mathrm{kPa}$. In order to achieve this objective, the height of the specimen was allowed to change, which resulted in the vertical dilation as shown in Figure 8. It is noted that, in SST, the axial normal load varies during shear process to maintain the specimen height at constant, the purpose of which is to simulate the confinement that exists in the field pavements.

Failure of the asphalt concrete under shear load occurred on a diagonal sliding plane as shown in Figure 9. This agrees with the normal understanding about the shear failure of the asphalt mixture, however, it must be noted that this shear test configuration has several limitations: 1) a high stress concentration is produced at the edges of the endcaps and the specimen (i.e., the area marked by the red circles in Figure 9). The bottom corner is subjected to a high compressive stress while the top corner is in a high tensile stress; 2) according to continuum mechanics, two symmetrical shear stresses should appear on the adjacent orthogonal planes simultaneously; however, only one shear load was applied on the horizontal plane, whereas no shear load was applied on the vertical plane. These limitations lead to complex stress distribution in the sample and it is believed that the stress states shown in Equation 23 only apply to the middle inner part of the asphalt concrete sample.

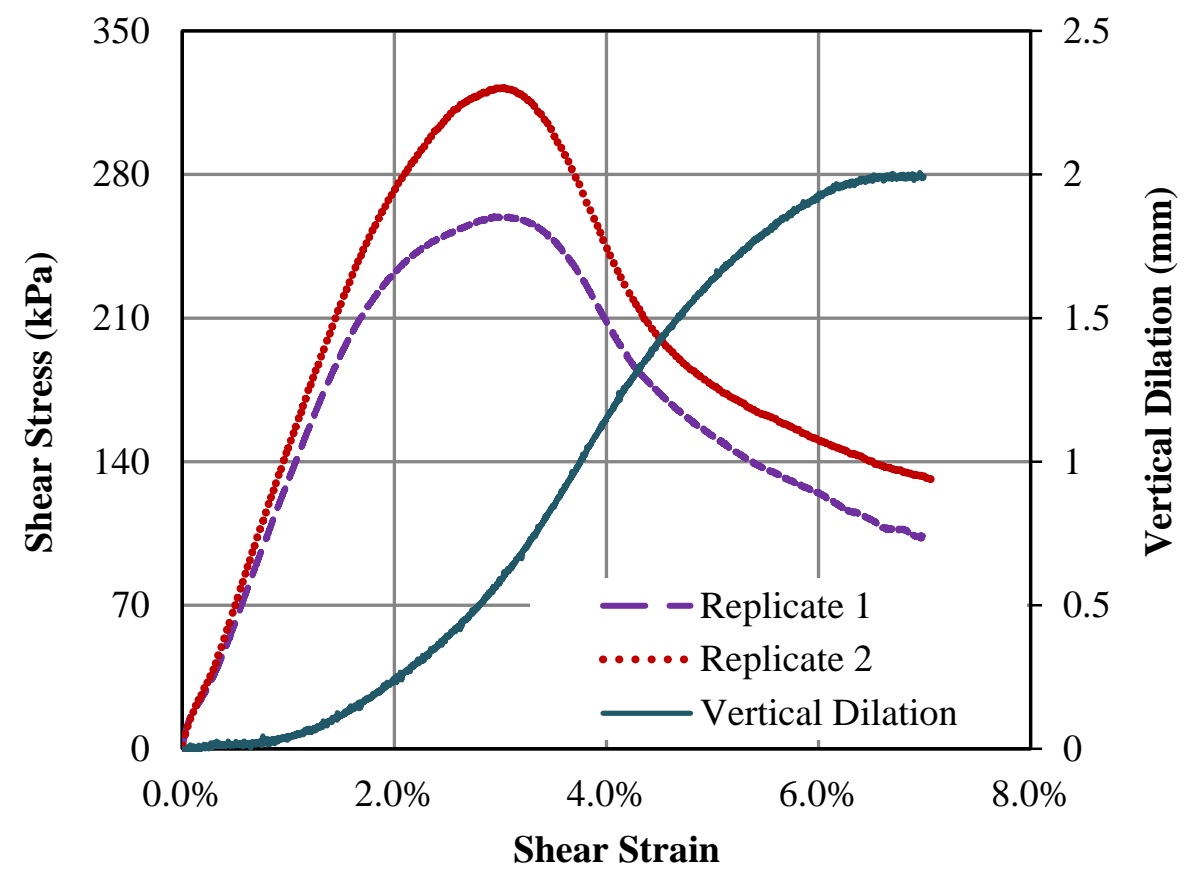

Fig.8 Shear stress versus strain curves and vertical dilation of asphalt concretes (7\%, Case No. E) 


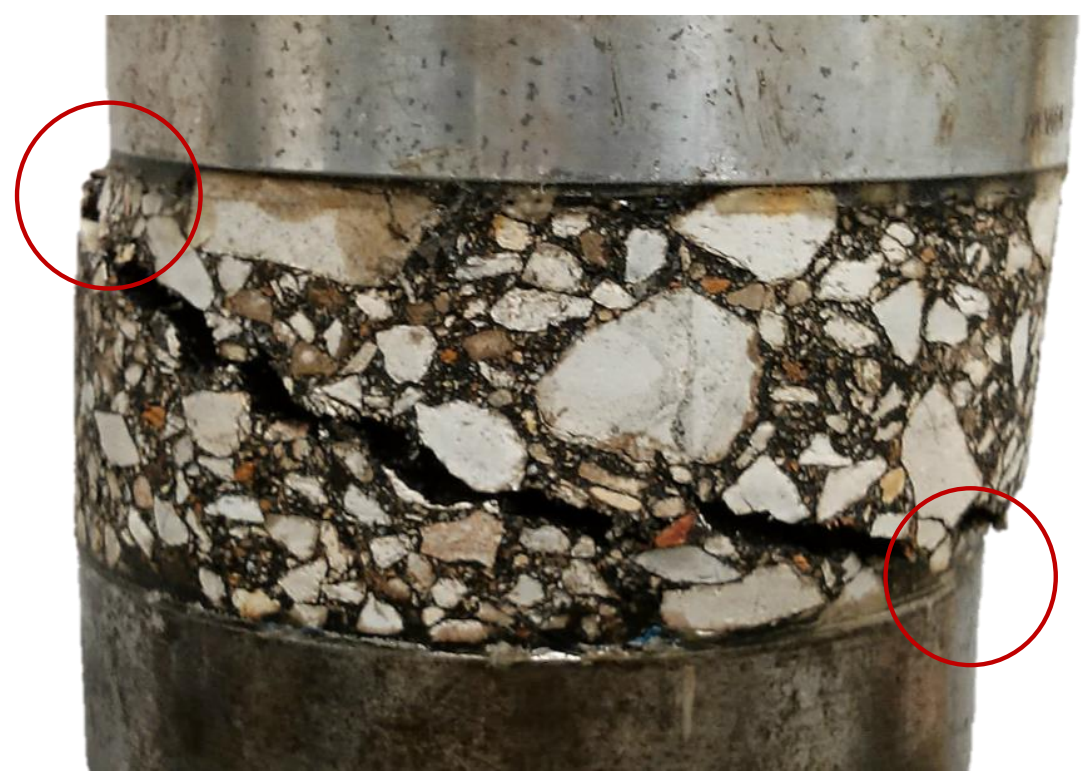

Fig.9 Diagonal shear failure plane of an asphalt concrete in octahedral shear strength tests

Aggregate abrasion was observed on the shear failure surface. As shown in Figure 10, many white spots were identified by separating the specimen apart along the failure plane after the shear tests. The white spots were caused by the abrasion between the limestone aggregates during the sliding of the failure surface under the shear load. This demonstrates that the interlock and friction between aggregates provide the primary resistance to the shear deformation to the asphalt concrete. This shear resistance was characterized by the function $\rho(\theta, d)$ of the GD-P model. In contrast, the authors performed direct tensile tests on the same materials and no white spots were found on the fracture surface, suggesting cohesion of the asphalt mastic was the major source of the resistance to the tensile load.

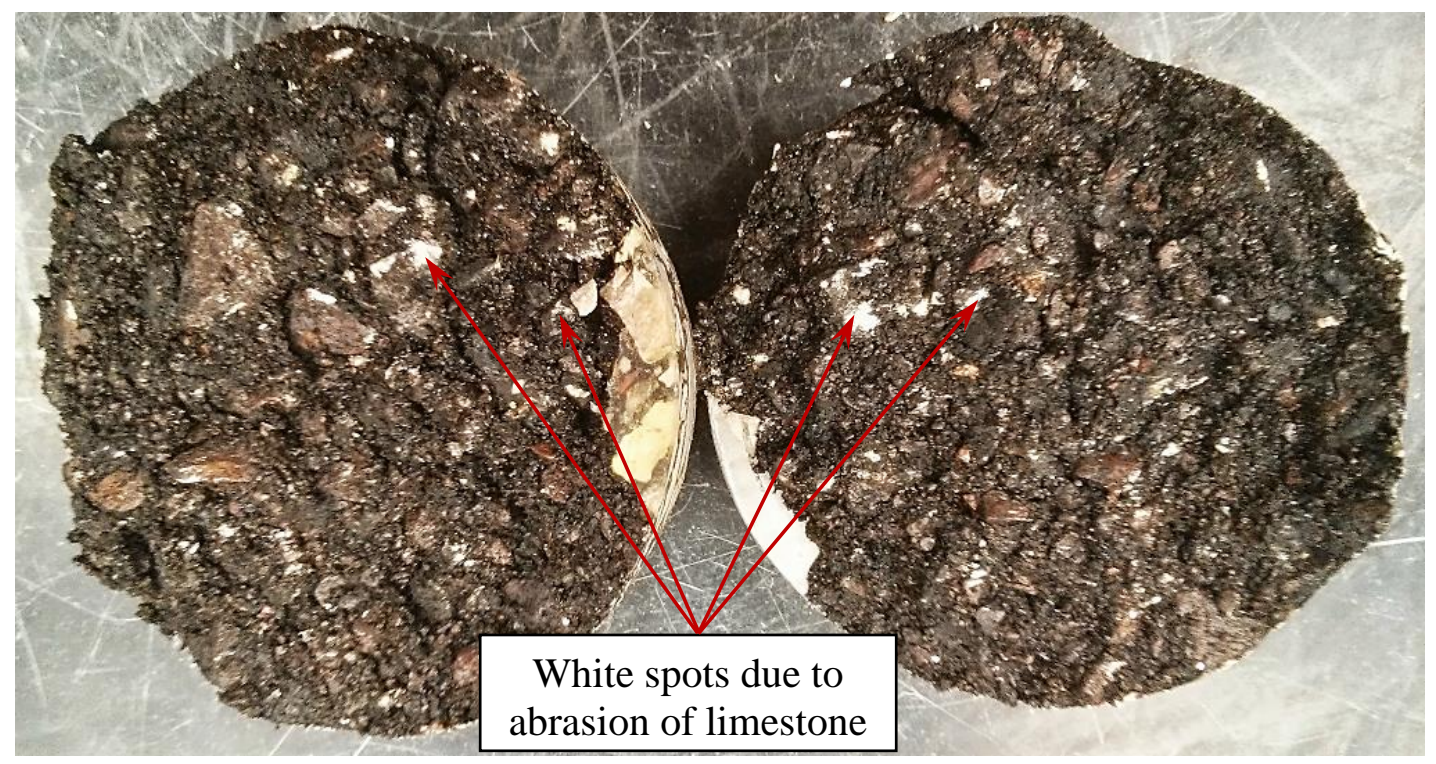

Fig.10 White spots due to abrasion of limestone aggregates on shear failure surfaces of asphalt concrete 


\subsection{Validations of GD-P and ED-P with Test Data}

The yield shear stress data for all tested asphalt concrete specimens were employed to validate the proposed GD-P and the existing ED-P models. To plot the yield surface on the octahedral plane, the following stress invariants were calculated based on the measurements of $\sigma, p$, and $\tau$ :

$$
\left\{\begin{array}{l}
I_{1}=\sigma_{k k}=\sigma+3 p \\
J_{2}=\frac{1}{2} S_{i j} S_{j i}=\frac{1}{3} \sigma^{2}+\tau^{2} \\
J_{3}=\operatorname{det}\left(S_{i j}\right)=\frac{2}{27} \sigma^{3}+\frac{1}{3} \sigma \tau^{3}
\end{array}\right.
$$

Then the Load angle $(\theta)$ was calculated according to Equation 7, and the distance between a yield point and the coordinate origin on the octahedral plane was the yield octahedral shear stress that was determined as $\tau_{\text {oct }}=\sqrt{2 J_{2}}$. Thus the horizontal and vertical coordinates of a yield point on a rectangular coordinate were calculated by $\tau_{\text {oct }} \sin \theta$ and $\tau_{o c t} \cos \theta$, respectively. Based on this method, the yield points on the octahedral plane were plotted as the circle points in Figures 11 and 12 which represent the yield octahedral shear stresses for the asphalt concrete with $4 \%$ and $7 \%$ air void contents, respectively. According to the test results in authors' previous study (Table 3 in Zhang, et al., 2013), the asphalt concrete with $4 \%$ air void content has a relatively larger cohesion (i.e., $191.9 \mathrm{kPa}$ ) compared to the asphalt concrete with $7 \%$ air void content (i.e., $93.9 \mathrm{kPa}$ ) whereas both have statistically the same internal friction angle (i.e., $\left.44^{\circ}\right)$. Figure 11 shows a larger size of the octahedral yield surface than Figure 12 while both show that the yield surfaces have the same shape on the octahedral plane. Therefore, one can conclude that material cohesion does not affect the shape of the octahedral yield surface which is a function of internal friction angle. Since different testing temperatures and loading rates cannot alter the material internal friction, a further conclusion is drawn that the testing temperature and loading rate only affect the size but not the shape of the yield surface on the octahedral plane. This is also the reason of that only one temperature and one shear loading rate were used in the octahedral shear strength tests.

In Figures 11 and 12, the predicted yield octahedral shear stresses were calculated using Equations 6 for the existing ED-P model and using Equation 20 for the proposed GD-P model, in which the internal friction angle was $44^{\circ}$ and the corresponding value of $d$ was $0.62 . \sigma_{1}$ stands for compression and $-\sigma_{3}$ stands for extension. A, B, C, D, E, F, and $\mathrm{G}$ represent different stress combinations of the normal stress and the confining pressure, as illustrated in Table 2. One can find from both Figure 11 and Figure 12 that the predictions of the GD-P yield surface model matched well with the experimentally determined yield octahedral shear stresses while the ED-P model over-predicted the yield stresses on the octahedral plane. The reason is that the ED-P model produces a non-convex yield surface when the material internal friction angle exceeds $22^{\circ}$, thus the ED-P model is not applicable to characterize the yield surface of the asphalt concrete which normally has a friction angle greater than $22^{\circ}$. The proposed GD-P model is an inherently convex yield surface model over the full range of the internal friction angle, which is a proper yield surface model for the asphalt concrete. 


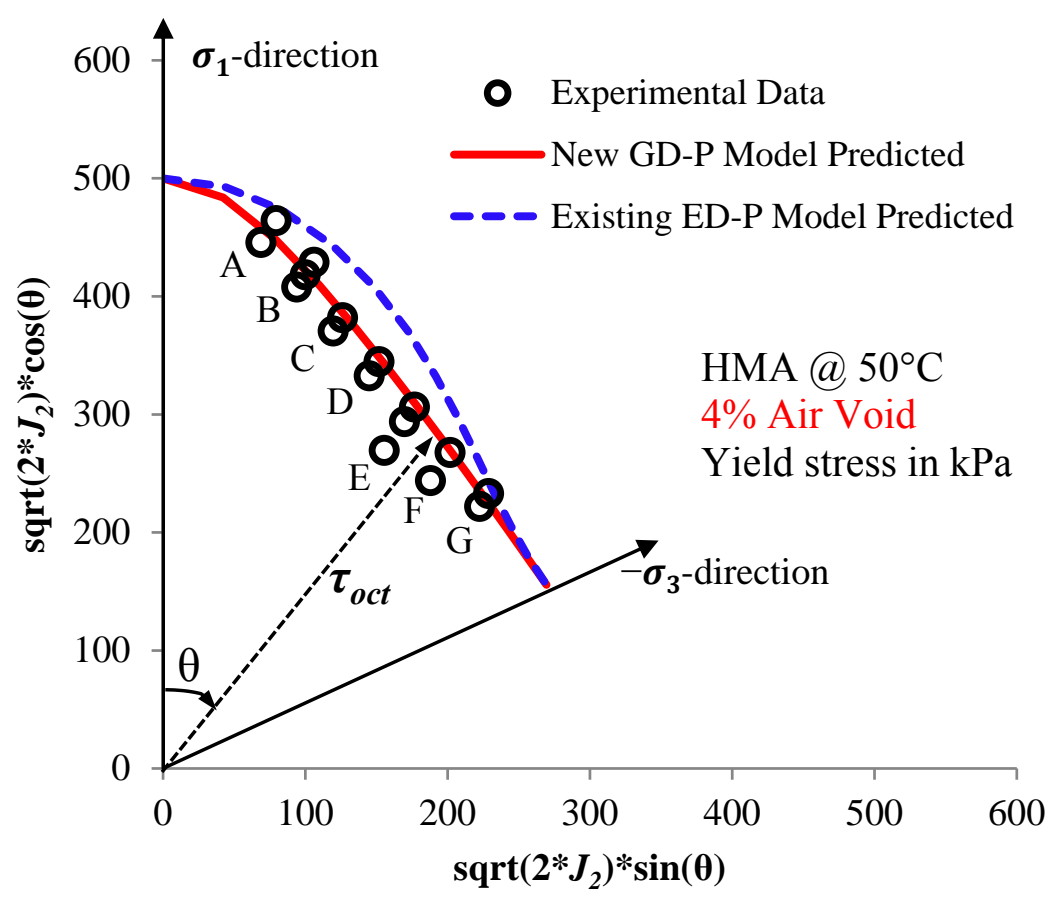

Fig.11 Comparisons of yield octahedral shear stresses between experimental data and GD-P, ED-P model predictions for asphalt concrete with $4 \%$ air void contents

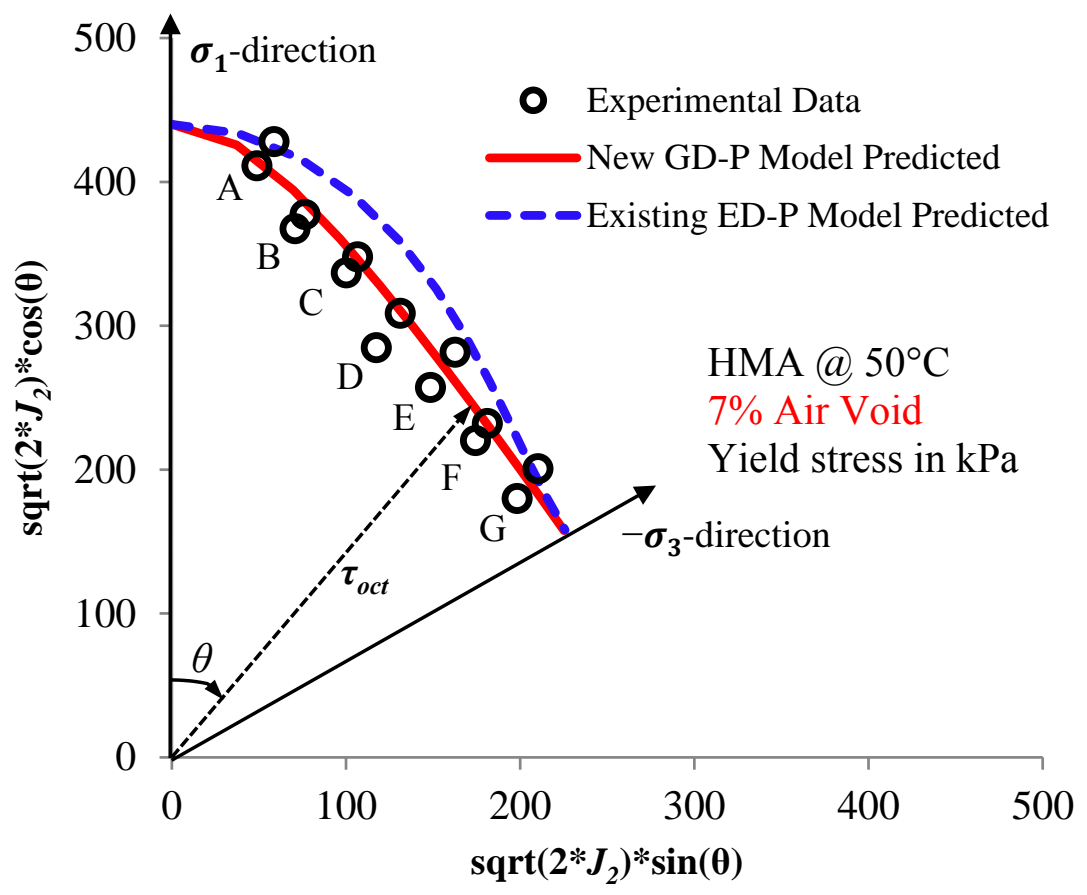

Fig.12 Comparisons of yield octahedral shear stresses between experimental data and GD-P, ED-P model predictions for asphalt concrete with $7 \%$ air void contents 
The over-prediction of the yield shear stress of the ED-P model may reduce the reliability of the rutting performance prediction as the rutting depth will be underestimated in an asphalt pavement analysis. Based on the results of Figures 11 and 12, the asphalt concrete of the field pavements will yield at a lower shear stress and start to develop permanent deformation earlier than the ED-P model prediction. Then, an under-predicted rutting depth is provided if using the ED-P model in the constitutive analysis of the asphalt pavements. Therefore, it is emphatically recommended to employ the GD-P yield surface model rather than the ED-P model in the viscoplastic analysis of the asphalt concrete.

More studies are recommended in the area of implementing the GD-P model in a rutting performance prediction of real asphalt pavements and validating the model in different loading conditions and field conditions. Due to the load limitation of the shear test machine, a relatively smaller size of specimen was used in this study. Thus a different (e.g., larger) size of the specimen may need to be tested to evaluate the size effect and determine the minimum dimension of the representative volume element (RVE) in a shear strength test of the asphalt concrete.

\section{Conclusions}

An intensive literature review was performed on the fundamental material properties that are associated with the rutting development of an asphalt concrete. Six existing yield surface models in the literature were evaluated and found to have limitations in the characterization of 1) temperature and strain rate dependent strain hardening, 2) anisotropy of asphalt concrete, 3) smoothness of the yield surface and 4) convexity of the yield surface. The authors removed the first limitation in a previous study (Zhang et al. 2013). That development led to the Generalized Drucker-Prager (GD-P) yield surface model proposed in this study to eliminate the other three limitations.

The proposed GD-P model was formulated based on fabric tensor modified stresses to account for the inherent anisotropy of the asphalt concrete that is caused by the inclined aggregates. A smooth and convex octahedral yield surface function was developed for the GD-P model to characterize the full range of the internal friction angles from $0^{\circ}$ to $90^{\circ}$. In comparison, the Extended Drucker-Prager (ED-P) is applicable only for a material that has an internal friction angle less than $22^{\circ}$ due to the convexity criterion of the yield surface. The GD-P is a general yield surface model and it coincides with the apices of the Mohr-Coulomb yield surface on the octahedral plane and can be regarded as a smoothed Mohr-Coulomb yield surface. Special cases of the GD-P model include the existing models such as the Drucker-Prager model and the Matsuoka-Nakai model.

Laboratory tests were performed on asphalt concrete specimens to evaluate the anisotropic effect on the yield surface and to validate the proposed GD-P model. The following conclusions were obtained:

- The yield stress of an isotropic yield surface model is greater in compression and less in extension than that of an anisotropic model. Thus the viscoplastic deformation of an asphalt concrete is under-predicted, which may lead to an underestimation of the rutting depth of an pavement if using an isotropic yield surface model.

- Yield stresses predicted by the GD-P model on the octahedral plane matched well with the experimental results determined by the octahedral shear strength tests at different normal and confining pressures. In contrast, the 
ED-P model over-predicted the octahedral yield stresses, which can result in the under-prediction of the permanent deformation.

In summary, the rutting depth of an asphalt pavement will be underestimated without considering anisotropy and convexity of the yield surface for asphalt concrete. The GD-P model was validated to be capable of overcoming the limitations of the existing models and address the anisotropy and convexity of the yield surface for the asphalt concrete.

\section{Acknowledgement}

The authors would like to acknowledge the financial support from the U.S. Department of Transportation (USDOT) and the Texas state general revenue funds through Southwest Region University Transportation Center (SWUTC No. 600451-00006). The validation shear tests of this study are based upon the work supported by the National Science Foundation under Grant No. 0943140.

\section{Appendix A: Derivation of Function $\rho(d, \theta)$ in GD-P Model}

The resistance of an asphalt concrete to permanent deformation is provided by the material cohesion of asphalt mastic and the friction of aggregate skeleton. In general, material cohesion is an isotropic property and it only affects the size of a yield surface. The friction of the aggregate skeleton contributes the size and shape of the yield surface. Since $\rho(d, \theta)$ in GD-P model determines the shape of the yield surface on the octahedral plane, it should depend only on the aggregate skeleton of the mixture which behaves similarly to unbound aggregates or sands. This thinking urges the authors to take advantage of the yield surface model for cohesionless sand to model the yielding of aggregate skeleton of the asphalt concrete.

Matsuoka-Nakai (M-N) (1974; Matsuoka and Nakai 1985) model has been used to model the yield surface of the cohesionless sands and it is an inherently smooth and convex yield surface. Using the modified stress invariants, the Matsuoka-Nakai model is expressed as:

$$
\frac{\bar{I}_{1} \bar{I}_{2}}{\bar{I}_{3}}=k
$$

where $\bar{I}_{1}\left(=\bar{\sigma}_{k k}\right), \bar{I}_{2}\left(=\frac{1}{2}\left(\bar{\sigma}_{i i} \bar{\sigma}_{j j}-\bar{\sigma}_{i j} \bar{\sigma}_{j i}\right)\right)$ and $\bar{I}_{3}\left(=\operatorname{det}\left(\bar{\sigma}_{i j}\right)\right)$ are first, second and third invariants of the modified stress tensor $\left(\bar{\sigma}_{i j}\right)$. Parameter $k$ can be expressed in terms of the material internal friction angle (or the extension ratio $d$ ) as follows (Bardet 1990):

$$
k=\frac{9-\sin ^{2} \phi}{1-\sin ^{2} \phi}=\frac{9 d}{(2 d-1)(2-d)}
$$


To convert M-N model to an expression in terms of $\sqrt{\bar{J}_{2}}$ and $\bar{I}_{1}$ that are the first order of the stress, $\bar{I}_{2}$ and $\bar{I}_{3}$ are written as:

$$
\begin{aligned}
& \bar{I}_{2}=\frac{1}{3} \bar{I}_{1}^{2}-\bar{J}_{2} \\
& \bar{I}_{3}=\bar{J}_{3}-\frac{1}{3} \bar{I}_{1} \bar{J}_{2}+\frac{1}{27} \bar{I}_{1}^{3}
\end{aligned}
$$

Substituting Equations A2, A3, and A4 into Equation A1 obtains:

$$
2(d-1)^{2} \bar{I}_{1}^{3}-6\left(d^{2}-d+1\right) \bar{I}_{1} \bar{J}_{2}+27 d \bar{J}_{3}=0
$$

Equations 3 and 8 in the text relate $\alpha$ to $d$ as follows:

$$
\alpha=\frac{1-d}{\sqrt{3} d}
$$

Introducing Equation A6 and the Lode angle defined by Equation 7 into Equation A5 gives:

$$
d^{2}\left(\alpha \bar{I}_{1}\right)^{3}-\left(d^{2}-d+1\right) \bar{J}_{2}\left(\alpha \bar{I}_{1}\right)+(1-d)\left(\bar{J}_{2}\right)^{3 / 2} \cos (3 \theta)=0
$$

Equation A7 is a transformed expression for the Matsuoka-Nakai model, which does not account for the temperature and strain rate dependent cohesion and strain hardening. To consider these material properties of asphalt concrete, the term $\kappa a_{T} a_{\dot{\varepsilon}}$ is added and Equation A7 becomes:

$$
d^{2}\left(\alpha \bar{I}_{1}+\kappa a_{T} a_{\dot{\varepsilon}}\right)^{3}-\left(d^{2}-d+1\right) \bar{J}_{2}\left(\alpha \bar{I}_{1}+\kappa a_{T} a_{\dot{\varepsilon}}\right)+(1-d)\left(\bar{J}_{2}\right)^{3 / 2} \cos (3 \theta)=0
$$

To acquire an expression with the first order of stress, Equation A8 is treated as a cubic equation that has a variable of $\alpha \bar{I}_{1}+\kappa a_{T} a_{\dot{\varepsilon}}$. Solving this cubic equation gives a new yield surface function as:

$$
\sqrt{\bar{J}_{2}} \rho(\theta, d)-\alpha \bar{I}_{1}-\kappa a_{T} a_{\dot{\varepsilon}}=0
$$

where

$$
\rho(\theta, d)=\mu \cos \left[\frac{1}{3} \arccos (\gamma \cos 3 \theta)\right]
$$

and 


$$
\left\{\begin{array}{l}
\mu=\frac{2 \sqrt{1-d+d^{2}}}{\sqrt{3} d} \\
\gamma=-\frac{3 \sqrt{3}}{2} \frac{(1-d) d}{\left(1-d+d^{2}\right)^{3 / 2}}
\end{array} \quad\left(d=\frac{3-\sin \phi}{3+\sin \phi}\right)\right.
$$

Equation A9 is the GD-P yield surface model proposed in this study. Parameters $\mu$ and $\gamma$ are related to $d$ that is a function of internal friction angle $(\phi)$. Equations A10 and A11 demonstrate that the shape of GD-P model on the octahedral plane only depends on the internal friction angle of the material that is determined by aggregate skeleton. $\theta$ is the Lode angle and $\theta=0$ indicates triaxial compression and $\theta=\frac{\pi}{3}$ implies triaxial extension. Using Equations A10 and A11, one can get the following relations:

$$
\begin{cases}\rho(\theta=0)=\mu \cos \left[\frac{1}{3} \arccos (\gamma)\right]=1 & \text { in compression } \\ \rho\left(\theta=\frac{\pi}{3}\right)=\mu \cos \left[\frac{1}{3} \arccos (-\gamma)\right]=\frac{1}{d} \quad \text { in extension }\end{cases}
$$

\section{References}

Argyris JH, Faust G, Szimmat J, Warnke EP, Willam KJ (1974) Recent developments in the finite element analysis of prestressed concrete reactor vessels. Nuclear Engineering and Design 28:42-75. doi:10.1016/00295493(74)90088-0

Bahuguna S, Panoskaltsis VP, Papoulia KD (2006) Identification and modeling of permanent deformations of asphalt concrete. Journal of Engineering Mechanics 132:231-239. doi:10.1061/(asce)0733-9399(2006)132:3(231)

Bardet JP (1990) Lode dependences for isotropic pressure-sensitive elastoplastic materials. Journal of Applied Mechanics 57:498-506

Bigoni D, Piccolroaz A (2004) Yield criteria for quasibrittle and frictional materials. International Journal of Solids and Structures 41:2855-2878. doi:10.1016/j.ijsolstr.2003.12.024

Birgisson B, Soranakom C, Napier J, Roque R (2003) Simulation of fracture initiation in hot-mix asphalt mixtures. Transportation Research Record: Journal of the Transportation Research Board, No. 1849, Transportation Research Board of the National Academies, Washington, DC.

Bonaquist R, Witczak M (1996) Plasticity modeling applied to the permanent deformation response of granular materials in flexible pavement systems. Transportation Research Record: Journal of the Transportation Research Board, No. 1540, Transportation Research Board of the National Academies, Washington, D.C.

Chen WF, Mizuno E (1990) Nonlinear analysis in soil mechanics, theory and implementation. Elsevier Science Ltd., Amsterdam, The Netherlands 
Darabi MK, Abu Al-Rub RK, Masad EA, Huang C-W, Little DN (2011) A thermo-viscoelastic-viscoplasticviscodamage constitutive model for asphaltic materials. International Journal of Solids and Structures 48:191207. doi:10.1016/j.ijsolstr.2010.09.019

Darabi MK, Abu Al-Rub RK, Masad EA, Huang C-W, Little DN (2012a) A modified viscoplastic model to predict the permanent deformation of asphaltic materials under cyclic-compression loading at high temperatures. International Journal of Plasticity 35:100-134. doi:http://dx.doi.org/10.1016/j.ijplas.2012.03.001

Darabi MK, Abu Al-Rub RK, Masad EA, Little DN (2012b) A thermodynamic framework for constitutive modeling of time- and rate-dependent materials. Part ii: Numerical aspects and application to asphalt concrete. International Journal of Plasticity 35:67-99. doi:http://dx.doi.org/10.1016/j.ijplas.2012.02.003

Desai CS, Somasundaram S, Frantziskonis G (1986) A hierarchical approach for constitutive modelling of geologic materials. International Journal for Numerical and Analytical Methods in Geomechanics 10:225-257

Dessouky SH, Masad EA The development of a microstructural-based continuum model for hot mix asphalt. In: Lytton RL (ed) Asphalt Concrete: Simulation, Modeling, and Experimental Characterization, Baton Rouge, LA, United States, 2006. Geotechnical Special Publication. American Society of Civil Engineers, pp 44-52

Drucker DC (1959) A definition of stable inelastic material. Journal of Applied Mechanics 26:101-106

Fwa TF, Tan SA, Low BH (1997) Relating triaxial test properties of asphalt mixtures to mix parameters determined by marshall stability test. J Test Eval 25:471-478

Fwa TF, Tan SA, Zhu LY (2004) Rutting prediction of asphalt pavement layer using c-phi model. Journal of Transportation Engineering 130:675-683. doi:10.1061/(asce)0733-947x(2004)130:5(675)

Gao Z, Zhao J, Yao Y (2010) A generalized anisotropic failure criterion for geomaterials. International Journal of Solids and Structures 47:3166-3185. doi:http://dx.doi.org/10.1016/j.ijsolstr.2010.07.016

Haythornthwaite RM (1985) A family of smooth yield surfaces. Mechanics Research Communications 12:87-91

Huang B, Mohammad L, Wathugala G (2004) Application of a temperature dependent viscoplastic hierarchical single surface model for asphalt mixtures. Journal of Materials in Civil Engineering 16:147-154

Jiang J, Pietruszczak S (1988) Convexity of yield loci for pressure sensitive materials. Computers and Geotechnics $5: 51-63$

Kong Y, Zhao J, Yao Y (2013) A failure criterion for cross-anisotropic soils considering microstructure. Acta Geotech 8:665-673. doi:10.1007/s11440-012-0202-7

Lin F-B, Bazant ZP (1986) Convexity of smooth yield surface of frictional material. Journal of Engineering Mechanics 112:1259-1262

Maiolino S (2005) Proposition of a general yield function in geomechanics. Comptes Rendus Mecanique 333:279-284

Maiolino S, Luong MP (2009) Measuring discrepancies between coulomb and other geotechnical criteria: Druckerprager and matsuoka-nakai. 7th Euromech Solid Mechanics Conference, Lisbon, Portugal 2009-09-07

Masad E, Dessouky S, Little D (2007) Development of an elastoviscoplastic microstructural-based continuum model to predict permanent deformation in hot mix asphalt. International Journal of Geomechanics 7:119-130 
Masad E, Muhunthan B, Shashidhar N, Harman T (1998) Aggregate orientation and segregation in asphalt concrete. In: Papagiannakis AT, Schwartz CW (ed) Application of geotechnical principles in pavement engineering. Geotechnical special publication. Boston, MA, USA, pp 69-80

Matsuoka H, Nakai T Stress-deformation and strength characteristics of soil under three different principal stresses. In: Japan Society of Civil Engineers, 1974. pp 59-70

Matsuoka H, Nakai T (1985) Relationship among tresca, mises, mohr-coulomb and matsuoka-nakai failure criteria. Soils and Foundations 25:123-128

Mortara G (2008) A new yield and failure criterion for geomaterials. Geotechnique 58:125-132

Mortara G (2010) A yield criterion for isotropic and cross-anisotropic cohesive-frictional materials. International Journal for Numerical and Analytical Methods in Geomechanics 34:953-977. doi:10.1002/nag.846

Muraya PM, Molenaar AAA, van de Ven MFC Contribution of asphalt mix components to permanent deformation resistance. In: Tutumluer E, AlQadi IL (eds) 8th International Conference on the Bearing Capacity of Roads, Railways and Airfields, Champaign, IL, 2009. pp 259-268

Oda M (1993) Inherent and induced anisotropy in plasticity theory of granular soils. Mechanics of Materials 16:35-45

Oda M, Nakayama H (1989) Yield function for soil with anisotropic fabric. Journal of Engineering Mechanics 115:89104

Oh J, Lytton RL, Fernando EG (2006) Modeling of pavement response using nonlinear cross-anisotropy approach. Journal of Transportation Engineering 132:458-468

Park D, Martin A, Lee H, Masad E (2005) Characterization of permanent deformation of an asphalt mixture using a mechanistic approach. KSCE Journal of Civil Engineering 9:213-218. doi:10.1007/bf02829052

Pickering DJ (1970) Anisotropic elastic parameters for soil. Geotechnique 20:271-276

Rutherford CJ (2012) Development of a multi-directional direct simple shear testing device for characterization of the cyclic shear response of marine clays. Texas A\&M University

Rutherford CJ, Biscontin G (2013) Development of a multi-directional simple shear testing device. Geotechnical Testing Journal 36. doi:10.1520/GTJ20120173

Saadeh S, Masad E, Little D (2007) Characterization of asphalt mix response under repeated loading using anisotropic nonlinear viscoelastic-viscoplastic model. Journal of Materials in Civil Engineering 19:912-924

Seibi A, Sharma M, Ali G, Kenis W (2001) Constitutive relations for asphalt concrete under high rates of loading. Transportation Research Record: Journal of the Transportation Research Board, No. 1767, Transportation Research Board of the National Academies, Washington, D.C.

Shaverdi H, Taha MR, Kalantary F (2013) Micromechanical formulation of the yield surface in the plasticity of granular materials. Journal of Applied Mathematics 2013:7. doi:10.1155/2013/385278

Somasundaram S, Desai C (1988) Modeling and testing for anisotropic behavior of soils. Journal of Engineering Mechanics 114:1473-1496. doi:doi:10.1061/(ASCE)0733-9399(1988)114:9(1473)

Sousa JB, Weissman SL (1994) Modeling permanent deformation of asphalt-aggregate mixes. Journal of Association of Asphalt Paving Technologists 63:224-257 
Subramanian V, Guddati MN, Richard Kim Y (2013) A viscoplastic model for rate-dependent hardening for asphalt concrete in compression. Mechanics of Materials 59:142-159. doi:http://dx.doi.org/10.1016/j.mechmat.2012.10.003

Sun L, Zhu H, Zhu Y (2013) Two-stage viscoelastic-viscoplastic damage constitutive model of asphalt mixtures. Journal of Materials in Civil Engineering 25:958-971. doi:10.1061/(ASCE)MT.1943-5533.0000646

Tan S-A, Low B-H, Fwa T-F (1994) Behavior of asphalt concrete mixtures in triaxial compression. J Test Eval 22:195203

Tashman L, Masad E, Peterson B, Saleh H (2002) Internal structure analysis of asphalt mixes to improve the simulation of superpave gyratory compaction to field conditions. Journal of Association of Asphalt Paving Technologists 70:605-645

Tashman L, Masad E, Zbib H, Little D, Kaloush K Anisotropic viscoplastic continuum damage model for asphalt mixes. In: Recent Advances in Materials Characterization and Modeling of Pavement Systems, 15th Engineering Mechanics Division Conference, New York, NY, 2004. American Society of Civil Engineers, pp 111-125

Tobita Y (1989) Fabric tensors in constitutive equations for granular materials. Soils and Foundations 29:91-104

Tobita Y, Yanagisawa E (1988) Contact tensor in constitutive model for granular materials. In: Satake M, Jenkins JT (ed) Micromechanics of granular materials. Elsevier Science Publishers B.V., Amsterdam, The Netherlands, pp 263-270

Tobita Y, Yanagisawa E (1992) Modified stress tensors for anisotropic behavior of granular materials. Soils and Foundations 32:85-99

TxDOT (2004) Standard specifications for construction and maintenance of highways, streets, and bridges. Texas Department of Transportation, Austin, TX

TxDOT (2008) Test procedure for design of bituminous mixtures. Texas Department of Transportation, Austin, TX

Van Eekelen HAM (1980) Isotropic yield surfaces in three dimensions for use in soil mechanics. International Journal for Numerical and Analytical Methods in Geomechanics 4:89-101. doi:10.1002/nag.1610040107

Wang L, Hoyos LR, Wang J, Voyiadjis G, Abadie C (2005) Anisotropic properties of asphalt concrete: Characterization and implications for pavement design and analysis. Journal of Materials in Civil Engineering 17:535-543

Wathugala G, Desai C (1993) Constitutive model for cyclic behavior of clays. I: Theory. Journal of Geotechnical Engineering 119:714-729. doi:doi:10.1061/(ASCE)0733-9410(1993)119:4(714)

Weissman SL, Harvey J, Sackman JL, Long F (1999) Selection of laboratory test specimen dimension for permanent deformation of asphalt concrete pavements. Transportation Research Record: Journal of the Transportation Research Board, Transportation Research Board of the National Academies, Washington, D.C.

Yang ZX, Lit XS, Yang J (2008) Quantifying and modeling fabric anisotropy of granular soils. Geotechnique 58:237248

Zhang Y, Luo R, Lytton RL (2011) Microstructure-based inherent anisotropy of asphalt mixtures. Journal of Materials in Civil Engineering 23:1473-1482 
Zhang Y, Luo R, Lytton RL (2012) Anisotropic viscoelastic properties of undamaged asphalt mixtures. Journal of Transportation Engineering 138:75-89

Zhang Y, Luo R, Lytton RL (2013) Characterization of viscoplastic yielding of asphalt concrete. Construction and Building Materials 47:671-679. doi:http://dx.doi.org/10.1016/j.conbuildmat.2013.05.075

Zhu H, Sun L (2013) A viscoelastic-viscoplastic damage constitutive model for asphalt mixtures based on thermodynamics. International Journal of Plasticity 40:81-100.

doi:http://dx.doi.org/10.1016/j.ijplas.2012.07.005 


\section{List of Figures}

Fig.1. Normalized yield surfaces of Mohr-Coulomb, Drucker-Prager, and Extended Drucker-Prager models on octahedral plane.

Fig.2. Three deminsional Extended Drucker-Prager (ED-P) yield surfaces with different internal friction angles.

Fig.3. Three deminsional Generalized Drucker-Prager (GD-P) yield surfaces wiht different internal friction angles.

Fig.4. Generalized Drucker-Prager (GD-P) yield surfaces on octahedral plane with different internal friction angle.

Fig.5. Measured modified vector magnitudes of asphalt concrete.

Fig.6. Generalized Drucker-Prager (GD-P) yield surfaces of asphalt concrete with different levels of anisotropy quantified by modified vector magnitude (i.e., $\Delta^{\prime}$ ).

Fig.7. Configuration of octahedral shear strength tests and loading conditions.

Fig.8. Shear stress versus strain curves and vertical dilation of asphalt concretes (7\%, Case No. E).

Fig.9. Diagonal shear failure plane of an asphalt concrete in octahedral shear strength tests.

Fig.10. White spots due to abrasion of limestone aggregates on shear failure surfaces of asphalt concrete.

Fig.11. Comparisons of yield octahedral shear stresses between experimental data and GD-P, ED-P model predictions for asphalt concrete with $4 \%$ air void contents.

Fig.12. Comparisons of yield octahedral shear stresses between experimental data and GD-P, ED-P model predictions for asphalt concrete with $7 \%$ air void contents. 